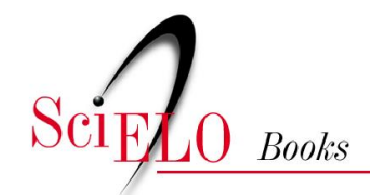

\title{
Agendas e dinâmicas de segurança andina e o conselho de defesa sul-americano
}

\author{
Augusto W. M. Teixeira Júnior
}

SciELO Books / SciELO Livros / SciELO Libros

TEIXEIRA JÚNIOR, AWM. Agendas e dinâmicas de segurança andina e o conselho de defesa sulamericano. In OLIVEIRA, RP., NOGUEIRA, SG., and MELO, FR., orgs. América Andina:

integração regional, segurança e outros olhares [online]. Campina Grande: EDUEPB, 2012. pp. 191209. ISBN 978-85-7879-185-8. Available from SciELO Books <http://books.scielo.org>.

\section{(c) (1) (2)(2)}

All the contents of this work, except where otherwise noted, is licensed under a Creative Commons Attribution-Non Commercial-ShareAlike 3.0 Unported.

Todo o conteúdo deste trabalho, exceto quando houver ressalva, é publicado sob a licença Creative Commons Atribuição Uso Não Comercial - Partilha nos Mesmos Termos 3.0 Não adaptada.

Todo el contenido de esta obra, excepto donde se indique lo contrario, está bajo licencia de la licencia Creative Commons Reconocimento-NoComercial-CompartirIgual 3.0 Unported. 
Parte II

Segurança na Região Andina 



\title{
Agendas e dinâmicas de segurança andina e o conselho de defesa sul-americano
}

\author{
Augusto W. M. Teixeira Júnior
}

\section{Resumo}

O presente artigo analisa a criação do Conselho de Defesa Sul-Americano (CDS) à luz de dinâmicas e agendas de segurança da região Andina. A partir da explanação sobre o conflito entre Colômbia, Equador e Venezuela em 2008, o texto aborda o modo como as deficiências dos mecanismos hemisféricos e regionais de prevenção e resolução de conflitos no contexto da invasão colombiana ao Equador contribuíram para o surgimento do CDS. A discussão não é apenas útil para entender a emergência do Conselho, mas permite compreender a formação da sua agenda e o escopo de atuação. $\mathrm{O}$ artigo promove uma análise política da formação do Conselho de Defesa Sul-Americano da Unasul tendo por base a crise entre Colômbia, Equador e Venezuela e os seus efeitos para a região. 


\section{Abstract}

This chapter discusses the creation of the South American Defense Council (SADC) in relation to the security dynamics and agenda of the Andean region. Departing from the discussion of the conflict between Colombia, Ecuador and Venezuela in 2008, the paper shows how the failure in hemispheric and regional mechanisms of conflict prevention and resolution, in the context of Colombian invasion of Ecuador, is related to the emergence of SADC. This discussion is not only useful for understanding the emergence of the Council, but allows understanding the formation of SADC's agenda and scope of action. This chapter does a political analysis of the formation of UNASUR South American Defense Council in as related to the crisis between Colombia, Ecuador and Venezuela and its effects to the region.

\section{Introdução}

Em dezembro de 2008, durante a Cúpula Extraordinária da Unasul ${ }^{1}$ foi criado o Conselho de Defesa Sul-Americano (CDS). Fruto de intensas negociações político-diplomáticas entre os 12 países da região, o CDS surgiu como iniciativa regional para estimular e aprofundar o diálogo e a cooperação em matéria de defesa na América do Sul. Distinto de iniciativas anteriores que se destacaram como arranjos ad hoc, a exemplo do Grupo de Contadora, Apoio e Grupo do Rio, o Conselho de Defesa emerge com o ineditismo e o potencial

1 União das Nações Sul-Americanas. 
de rivalizar com o sistema interamericano de defesa, de caráter hemisférico, em especial o sistema da Organização dos Estados Americanos (OEA).

Ao lado de seu caráter inovador no cenário regional, outros aspectos instigam à reflexão, como o seu contexto de criação e a formação de sua agenda de cooperação em defesa. Tendo sido criado no ano de 2008, o Conselho surge no esteio de crises diplomáticas e militares regionais, dentre as quais se destacam a invasão e ataque a acampamento das FARC por tropas colombianas em território equatoriano ${ }^{2}$ e a crise separatista no departamento de Pando, Bolívia. Embora motivados por razões distintas, ambos os conflitos compartilham o fato de serem localizados na sub-região andina, foco de instabilidades e tensões na América do Sul, em especial após o apaziguamento entre as três potências platinas, Argentina, Brasil e Chile.

O texto que segue buscará discutir o impacto das dinâmicas de (in)segurança andina para a criação e formação da agenda de cooperação do Conselho de Defesa da Unasul. Para tal, partirá daquilo que considera uma conjuntura crítica: a crise diplomática e militar envolvendo Colômbia, Equador e Venezuela. Dado o escopo e espaço do texto, não será possível explicitar os mecanismos causais da criação e formação da agenda do CDS, mas esperamos poder demonstrar como as preferências de Colômbia e Equador, em especial no contexto dos efeitos da mencionada crise, afetaram a agenda do Conselho de Defesa Sul-Americano.

2 Evento o qual nos iremos referir como crise andina. 


\section{Mudança no centro gravitacional da (in)segurança sul-americana}

Embora exibindo menos conflitos interestatais (guerras e crises violentas) do que outras regiões a América do Sul é um espaço marcado por tensões, embora nem sempre exiba uma expressão militarizada. As peculiaridades das dinâmicas de segurança na América do Sul intrigaram vários pesquisadores, intrigados para entender as razões da baixa incidência de guerras interestatais na região. Entre os quais se destacam Kacowitz (1998) sobre a "Paz Negativa" na América do Sul, Hurrell (1998) e a problematização da emergência de uma "comunidade de segurança" na região, Mares (2001) e a demonstração das especificidades do uso do poder militar nos conflitos na América Latina e do Sul. No conjunto desta literatura, Buzan e Waever (2003) talvez tenham sido os autores que obtiveram mais sucesso em desenvolver uma explicação mais profunda sobre o estado da segurança no subcontinente sul-americano. A partir de sua "Teoria dos Complexos Regionais de Segurança”, os pesquisadores acima citados lograram em separar a América do Sul em dois sub-complexos, o Norte Andino ${ }^{3}$ e Cone Sul $l^{4}$.

3 Do qual fazem parte Peru, Equador, Colômbia, Venezuela e Guiana. Notar que esta classificação incorpora a região amazônica como parte de uma grande região Andina.

4 Composto pela Argentina, Brasil, Chile. De acordo com os autores, Paraguai, Uruguai e Bolívia fazem parte do sub-complexo, especialmente na condição de estados-tampão (2003, p.317). Deve-se notar, porém, casos como o da Bolívia, que além de fazer parte do bloco ALBA, passa a ter a sua agenda de segurança cada vez mais moldada pelo sub-complexo andino. 
Desde o século XIX até o final da Guerra Fria, a dinâmica de segurança sul-americana foi fortemente influenciada pela rivalidade entre as potências regionais, como Argentina e Brasil. Porém, o apaziguamento e a redução das tensões entre estes países, como também ocorrido com o Chile e Peru, resultou na ausência de guerra entre os países do Cone Sul. Paralelo a este processo, a região andina manteve intactos problemas longevos, como a existência de grupos insurgentes e guerrilhas, disputas territoriais e o narcotráfico. O que queremos enfatizar é que é possível notar na América do Sul uma mudança no centro gravitacional das principais fontes de ameaças, riscos e insegurança. A fonte de instabilidade regional muda do sub-complexo do Cone Sul para o sub-complexo andino. Como efeito mais direto, observa-se a regionalização da insegurança andina para toda a América do Sul. O caso mais evidente deste fenômeno talvez seja o espraiamento do conflito andino e os seus efeitos para a região.

Embora a Colômbia esteja em guerra civil há mais de 40 anos, os seus impactos foram sentidos regionalmente com mais força a partir da virada dos anos 2000. Neste momento, o conflito interno colombiano foi articulado com a lógica estadunidense da Guerra Contra as Drogas, ao lado de um movimento mais amplo de tentativa de influenciar a agenda de segurança da América Latina para as então chamadas "novas ameaças", em especial o narcotráfico e, após o 11 de Setembro, o terrorismo.

Com a implementação do Plano Colômbia a partir de 1999 e com a plena militarização da luta com o Plano Patriota, a guerra contra as guerrilhas passa por uma 
transformação doutrinária. A luta do governo Uribe contra as FARC $^{5}$ passa a ser travada à luz da doutrina de contrainsurgência. Sistematizada e apresentada ao público no contexto da Política de Defesa Segurança Democrática ${ }^{6}$, de 2003, esta concepção estratégica gerou resultados como a modernização e transformação das Forças Armadas colombianas. Deste período até o presente, as $\mathrm{FFAA}^{7}$ daquele país têm sido transformadas em uma força de alta mobilidade e eficiência na condução da luta contrainsurgência. Incidindo também sobre a Marinha, esta passou a ser predominantemente uma força naval de águas marrons ${ }^{8}$.

Apesar do custo humano da luta armada e dos impactos regionais de sua transformação e evolução, o resultado tem sido favorável aos governos colombianos. No entanto, os custos deste processo colocaram a região em situações onde a segurança regional foi seriamente ameaçada pela possibilidade de escalada de um conflito regional entre Colômbia, Equador e Venezuela, sobre o qual nos referiremos como Crise Andina.

\section{A Crise Andina como Conjuntura Crítica}

Ao implementar o Plano Colômbia e Patriota na guerra de contrainsurgência contra as FARC e demais grupos não- estatais, a Colômbia adotou a estratégia de "assassinatos seletivos", buscando desarticular as lideranças das FARC com a

\footnotetext{
5 Forças Armadas Revolucionárias da Colômbia.

6 Disponível em: <http://www.resdal.org/Archivo/d00001f6.htm>.

7 Sigla internacional para Forças Armadas.

8 Para mais detalhes, ver IISS (2010, p. 56).
} 
sua base. Com tal objetivo, na madrugada de 1 de março de 2008 deu-se início a "Operação Fênix". Tropas colombianas invadiram o espaço aéreo e território equatoriano com vistas a destruir um acampamento das FARC e eliminar Raúl Reyes, importante líder da guerrilha. Após bombardeio do acampamento realizado por avióes de ataque leve Super Tucano, tropas de terra tomaram o local e resgataram material de inteligência. Embora Bogotá tenha argumentado que a operação se deu no contexto de uma "perseguição quente", a rápida e violenta ação realizada pelas Forças Armadas Colombianas foi interpretada pelo Equador e por vários outros países sul-americanos como uma agressão à soberania e território equatoriano. De imediato, uma crise política e diplomática foi instalada arrastando os países da região e organizações internacionais para a tentativa de mediação e resolução.

Pouco após o desencadear da crise, o Presidente Uribe afirmou ter encontrado provas no acampamento que confirmavam o envolvimento de membros do governo venezuelano com a guerrilha colombiana, acusando-o de ser complacente com o "terrorismo". Além do crescimento da tensão diplomática e militar entre Colômbia e Equador, tendo este último aumentado de imediato o efetivo militar na fronteira com a Colômbia, o presidente venezuelano, Hugo Chavéz ordenou a movimentação de 10 batalhões para a fronteira colombiana, fechando também a representação diplomática da Venezuela em Bogotá (CAROLL; BRODIZINSKY, 2008). Embora o aumento da presença militar destes países na região de fronteira com a Colômbia não tenha levado a uma escalada e conflagração bélica, mudanças importantes foram sentidas na dimensão estratégica-militar. Um mês após o incidente, o Ministro da Defesa e os Comandantes do Exército e Força 
Aérea equatorianos foram substituídos. Os Comandos de Defesa Territorial foram substituídos por um novo Comando Central, construído com vistas a poder lançar forças-tarefas com missões específicas, em especial as de "soberania de fronteira" e "soberania energética" (IISS, 2010).

Apesar da importância deste episódio na história recente da região, houve situações de crise anteriores. Por que elas não produziram resultados semelhantes, como a criação de uma institucionalidade como o Conselho de Defesa SulAmericano? Se lembrarmos da Guerra de Cenepa, entre Equador e Peru, observaremos que foi um conflito onde uma crise escalou para a condição de guerra interestatal, envolvendo a mediação de vários países da região, os Estados Unidos e a OEA. Contudo, aquele evento não logrou em produzir uma nova institucionalidade que buscasse ser responsável pela gerência de conflitos e da segurança regional. Não que este conflito não tivesse reverberações internacionais prévias, há muito produziu efeitos nocivos na América do Sul, principalmente no Equador e na Venezuela (RAMÍREZ, 2009). Argumentamos, contudo, que a crise andina de 1 de março de 2008 constitui uma conjuntura histórica, um momento de transição, onde países importantes da América do Sul agiram diante dos efeitos da regionalização do conflito colombiano.

\section{0 desenvolvimento da crise diplomática e os mecanismos de mediação e solução de controvérsias}

Nas primeiras horas após a eclosão do conflito, começaram a agir os mecanismos diplomáticos, nacionais e multilaterais nas Américas. A crise, que inicialmente fora deflagrada na lógica de um conflito entre Governo e grupo armado 
não-estatal, espalhou-se para país fronteiriço, o Equador, contaminando a Venezuela. Após o ataque do dia 1 de março, o Brasil, OEA e o Grupo do Rio agiram no sentido de impedir uma escalada violenta da crise.

Num breve período de tempo, o governo equatoriano buscou junto a OEA sanções contra a ação colombiana (NOSSA; GOY, 2008), sendo respaldado em especial pelos membros da $\mathrm{ALBA}^{9}$. O processo de negociação se arrastou por meses, não havendo logro em conseguir as sanções contra a Colômbia. Isso se deveu em parte, pelo possível veto estadunidense na Organização dos Estados Americanos. O resultado imediato das negociações junto à OEA foi a aprovação de uma resolução pelo Conselho Permanente desta instituição, acertada por Colômbia e Equador. No documento, Bogotá admitia ter violado a integridade física e territorial do Equador e este, em troca da admissão formal de Bogotá, desistiu de pedir sanções à OEA contra a Colômbia (MIRANDA; DORLHIAC, 2008). Devido a posiçôes extremamente antagônicas, a resolução não logrou acalmar plenamente os ânimos. Mantidas as animosidades, os efeitos diplomáticos da ação militar colombiana fariam se sentir por mais tempo.

Conjuntamente à OEA, destacou-se a relevância do Grupo do Rio como espaço de mediação. No dia 07 de março, menos de uma semana após o ataque colombiano, deu-se a 20a Cúpula do Grupo do Rio. Mecanismo permanente de consulta internacional entre países da América Latina e Caribe, o Grupo abordou a questão da crise. Buscou impedir uma escalada entre os partícipes e abrir canais para

9 Aliança Bolivariana para os Povos da Nossa América. 
uma negociação diplomática que satisfizesse os anseios dos antagonistas centrais, Colômbia e Equador (FIORI, 2008). $\mathrm{Na}$ ótica do primeiro, à luz da lógica da "guerra ao terror", o ataque em Angostura estava de acordo com a perspectiva de "defesa preventiva" (SAINT-PIERRE, 2008). Na concepção equatoriana, o ataque colombiano foi lido na ótica do direito internacional, numa perspectiva westphaliana, tratou-se da invasão do seu território e da morte de nacionais. As duas posições diplomáticas e lógicas antagonistas mostraram-se difíceis de mediar, cabendo ao Brasil um papel especial.

Segundo Saint-Pierre (2008), foi destacada a atuação da diplomacia brasileira ao manter o conflito em caráter bilateral, afastando a Venezuela e os Estados Unidos de sua possível escalada. Seja no Grupo do Rio ou através do Itamaraty, o Brasil buscou evitar a escalada entre os respectivos países. Contudo nota-se um claro movimento de "regionalizar" a solução e mediação do conflito, seja trazendo-o para o Grupo do Rio, e posteriormente defendendo a União das Nações Sul-Americanas como local adequado para a sua mediação e solução (GIRALDI, 2010).

\section{As preferências em Defesa e Segurança de Colômbia e Equador e o Conselho de Defesa Sul-Americano}

Após a sua recente criação, em maio de 2008, a União das Nações Sul-Americanas passou a ser, cada vez mais, o ambiente preferencial para discutir e mediar as consequências da crise diplomática andina. Embora causada por um evento episódico, a crise e os seus efeitos se arrastaram pela região e fóruns diplomáticos por mais de 2 anos, acompanhando, em 
paralelo a criação da Unasul e posteriormente do Conselho de Defesa Sul-Americano, em dezembro do mesmo ano.

O contexto de criação do CDS se deu nas cinzas ainda quentes da contenda entre os países andinos em questão. Assim sendo, a sua emergência foi afetada pela disputa entre Colômbia e Equador pela definição da criação ou não do Conselho e posteriormente, sobre a sua agenda e atribuições. Embora a ideia básica sobre a criação do CDS tenha partido do Brasil, em especial da articulação entre a Presidência da República, a Secretaria de Assuntos Estratégicos (SAE) e com o Ministério da Defesa (TEIXEIRA JR, 2010), o processo de criação e institucionalização foi negociado com os demais países da região, não passando incólume às crises e tensões vividas neste espaço. ${ }^{10}$

Em abril de 2008, apenas um mês após a deflagração do conflito entre os três países andinos aqui discutidos, o então Ministro da Defesa do Brasil, Nelson Jobim, visitou a Venezuela (15 de abril) e a Colômbia e Equador (28 de abril) com o objetivo de apresentar e discutir a proposta brasileira do CDS (MEDEIROS FILHO, 2010). Embora contando com posturas mais favoráveis, como a do Equador e Venezuela ${ }^{11}$, o governo brasileiro não contou com o interesse imediato da Colômbia (BBC, 2008), vindo a aderir ao Conselho em julho daquele ano, após visita e negociação direta do Presidente Lula

$10 \mathrm{O}$ amadurecimento da proposta do CDS-Unasul passou pelos debates do Grupo de Trabalho para tal fim, criado em maio de 2008. Saint-Pierre e Castro (2008) apresentam uma interessante discussão sobre a recepção da proposta brasileira do CDS na América do Sul.

11 A Venezuela já havia realizado a tentativa de criar uma arquitetura regional de defesa, a OTAS (Organização do Tratado do Atlântico Sul). 
da Silva junto a Álvaro Uribe (JARDIM, 2008). Apesar do aceite colombiano, o governo de Bogotá atrelou a participação de seu país no órgão mediante três condições, sendo elas "a tomada de decisóes por consenso, a participação exclusiva das forças institucionais dos países membros e, por último, o "rechaço total aos grupos violentos"12.

A posição equatoriana, desde o início, foi de apoio a criação do Conselho de Defesa Sul-Americano. O governo de Quito entendia que a criação do CDS poderia ser útil como mecanismo de respeito e garantia do direito internacional, podendo possuir um potencial dissuasor de atitudes como a realizada pela Colômbia em 1 de março de 2008. Quito não apenas foi um entusiasta da proposta como teve um importante papel na criação e operacionalização do CDS quando à frente da Presidência Pro Tempore do CDS-Unasul, a partir de agosto de 2009. A atuação equatoriana no secretariado do CDS preocupou-se centralmente em avançar o debate e a implementação e criação de medidas de confiança mútua na região. Como aponta Pérez (2009), uma tarefa complexa, em virtude da existência de distintas concepções sobre segurança e defesa na região e a existência de conflitos e tensões latentes. No que concerne a implementação do CDS e de sua operacionalização, no Plano de Ações 2010-2011 (CDS, 2010), das 21 medidas, divididas em quatro eixos, o Equador foi responsável por sete delas. Ainda durante a gestão equatoriana, foram lançados dois volumes dos Cuadernos de Defensa, o primeiro sobre a modernização de Ministérios da Defesa, o segundo, versava acerca da confiança e segurança na América do Sul.

12 Op. Cit. 
Ao nos voltarmos ao Estatuto do Conselho de Defesa Sul-Americano da Unasul (CDS, 2008), poderemos observar a congruência de preferências exibidas pelo Equador e Colômbia na composição de objetivos e características da estrutura institucional. Primeiramente, o CDS não se coloca como legalmente divergente dos mecanismos de direito internacional e solução de controvérsias vigentes, como a Carta das Nações Unidas e a Carta da OEA (Artigo 2). Esta posição reforça tanto o ensejo equatoriano de reforço do direito internacional como a posição colombiana de não se afastar de institucionalidades das quais participam os EUA, como a OEA e a ONU. Ainda na sua seção Princípios, no Artigo 3, expõe um conjunto de medidas a serem defendidas que se coadunam com princípios consagrados tanto da diplomacia brasileira, como também são pleitos de países como o Equador, conduzindo à defesa da soberania. Porém, na mesma seção é colocado que o Estatuto do CDS "Afirma el pleno reconocimiento de las instituciones encargadas de la defensa nacional consagradas por las Constituciones de los estados miembros." Ou seja, não reconhece a legalidade e legitimidade de grupos insurgentes nos territórios nacionais, sendo assim o exercício da defesa nacional um dever que cabe apenas às forças constitucionais. Os Objetivos elencados no documento versam fundamentalmente sobre a criação de uma identidade comum em defesa na região, mas dizem respeito a melhora da percepção da segurança regional promovendo medidas de confiança mútua. Em Estrutura e Funcionamento, observa-se que está satisfeito o pleito colombiano pela tomada de decisões por consenso. 


\section{Considerações Finais}

O presente capítulo buscou discutir como o conflito entre Colômbia, Equador e Venezuela, desencadeado em 1 de março de 2008, influenciou a criação do Conselho de Defesa Sul-Americano da Unasul. O texto buscou esclarecer as razões do predomínio da questão das medidas de confiança mútua no CDS e como as dinâmicas de (in)segurança nos países andinos ganham força ao moldar as instituições e a agenda da segurança regional.

O capítulo inicia apresentando os traços que caracterizam a América do Sul como uma zona de paz, onde existe uma baixa incidência de guerras. Tal concepção foi problematizada quando trouxemos a "Teoria dos Complexos Regionais de Segurança”. Esta nos permite observar uma fratura estrutural na segurança regional sul-americana, entre o Norte Andino e o Cone Sul. Observamos que as principais fontes de ameaças na América do Sul mudam de lugar, do Sul do subcontinente para o Norte, sendo a sub-região andina uma área caracterizada pela instabilidade.

Para uma melhor compreensão de como a região andina torna-se importante para explicar as mudanças recentes na segurança regional, entre elas a própria criação do Conselho de Defesa Sul-Americano, escolhemos nos ater a crise diplomática entre Colômbia, Equador e Venezuela. $\mathrm{O}$ seguinte caso foi observado à luz da concepção neo-institucional sobre conjunturas críticas, onde se acredita que determinados eventos podem criar possibilidades de mudança política. Apresentamos como um conjunto de transformações, no setor de defesa e segurança da Colômbia, ajuda-nos a entender a 
Crise Andina e de como o surgimento de lógicas de segurança plenamente destoantes faz cada vez mais necessário uma instância de diálogo e cooperação como o CDS.

Esta avaliação torna-se mais clara quando apresentamos as dificuldades de resolução do conflito e na redução das animosidades entre os países envoltos na crise sob escrutínio. Embora tenham sido valorosos os esforços da OEA, do Grupo do Rio e de chancelarias nacionais, os efeitos da crise fizeram-se sentir por bastante tempo. Neste ponto, apresentamos como a política externa brasileira buscou "regionalizar" a resolução do conflito para um ambiente institucional distinto daqueles erguidos sob a lógica da segurança e defesa hemisférica. Neste momento do texto, buscamos mostrar que embora a proposta inicial de criação do CDS tenha partido do Brasil, as preferências no campo da defesa e da segurança de países como Colômbia, Equador e Venezuela foram importantes na criação de uma agenda para o CDS-Unasul.

Embora o presente trabalho não tenha podido discutir os mecanismos causais que explicariam com mais profundidade a relação entre a Crise Andina $(X)$ e a criação e agenda do CDS (Y), preocupamo-nos em estabelecer uma explanação que sustente a existência de uma correlação entre o evento (caso) e o resultado observado. Sugerimos mais estudos sobre o Conselho de Defesa Sul-Americano, em especial sobre como países como Colômbia, Venezuela e Brasil, que possuem concepções sobre Defesa muito distintas, operacionalizam o Conselho em consonância com os meios nacionais de defesa e segurança. 


\section{Referências}

BUZAN, Barry; WAVER, Ole. Regions and Powers: the structure of international security. Cambridge/New York: Cambridge University Press, 2003.

CARROLL, Rory; BRODIZINSKY, Sibylla. Chavez sends 10 battalions to Colombian border after killing of Farc commander. The Guardian, 3 mar. 2008. Disponível em: <http://www.guardian.co.uk/world/2008/mar/03/venezuela.colombia >. Acessado em: 10 fev. 2012.

\section{CDS. ESTATUTO DEL CONSEJO DE DEFENSA} SURAMERICANO DE LA UNASUR. Disponível em: $<$ http://www.unasurcds.org/index.php?option $=$ com_con tent\&view=article\&id=159\%3Aestatuto-del-consejo-de- defensa-suramericano\&catid $=57 \% 3$ Aespanol $\&$ Itemid $=18$ 9\&lang=pt >. Acesso em: 09 jan. 2012.

CDS. Plan de Acción 2010-2011. Disponível em: <http://www.cdsunasur.org/es/plan-de-accion/ plan-de-accion-2010-2011>.

COLÔMBIA ficará fora de Conselho de Defesa Sulamericano. BBC Brasil, 21 mai. 2008. Disponível: <http:// noticias.terra.com.br/mundo/noticias/0,OI2902007-EI8140,00-Colombia+ficara+fora+de+Conselho+de+Def esa+Sulamericano.html>. Acesso em: 15 fev. 2012.

FIORI, Mylena. Grupo do Rio discute amanhã solução para crise entre Equador e Colômbia. Agência Brasil, 06 
mar. 2008. Disponível em: <http://agenciabrasil.ebc.com. $\mathrm{br} /$ noticia/2008-03-06/grupo-do-rio-discute-amanha-solucao-para-crise-entre-equador-e-colombia $>$. Acesso em: 22 fev. 2012.

GIRALDI, Renata. Brasil defende mediação da Unasul na crise entre Venezuela e Colômbia. Agência Brasil, 27 jul. 2010. Disponível em: <http://www.itamaraty.gov.br/sala-de-imprensa/selecao-diaria-de-noticias/midias-nacionais/ brasil/agencia-brasil/2010/07/27/brasil-defende-mediacao-da-unasul-na-crise-entre >. Acesso em: 22 fev. 2012.

HURRELL, Andrew. An emerging security community in South America? In: ADLER, Emanuel; BARNETT, Michael (Orgs.). Security Communities. Nova York: Cambridge University Press, 1998. p. 228-264.

IISS. The Military Balance 2010: the annual assessment of global military capabilities and defense economics. London: IISS, 2010.

JARDIM, Claudia. Colômbia adere a Conselho de Defesa Sul-americano. BBC Brasil, 19 jul. 2008. Disponível em: <http://www.bbc.co.uk/portuguese/reporterbbc/ story/2008/07/080719_lulauribeconselho_cj_cg.shtml >. Acesso em: 24 fev. 2012.

KACOWICZ, Ariel M. Zones of Peace in the Third World: South America and West Africa in Comparative Perspective. SUNY series in global politics. New York: State University of New York Press, 1998. 
MARES, David R. Violent Peace: militarized interstate bargaining in Latin America. New York: Columbia University Press, 2001.

MIRANDA, Renata; DORLHIAC, Gabriella. Colômbia e Equador fecham acordo. O Estado de S. Paulo, 06 mar. 2008. Disponível em: <http://www.estadao.com. $\mathrm{br} /$ noticias/impresso,colombia-e-equador-fecham-acordo, 135625,0.htm>. Acesso em: 22 fev. 2012.

NOSSA, Leonencio; GOY, Leonardo. Equador cobra posição da OEA contra a Colômbia. O Estado de S. Paulo, 05 mar. 2008. Disponível em: <http://www.estadao.com.br/ noticias/internacional,equador-cobra-posicao-da-oea-contra-a-colombia,135182,0.htm >. Acessado em: 16 fev. 2012.

PÉREZ, Rosa Mercedes. Desafíos del Ecuador en la Presidencial del Consejo de Defensa Sudamericano, 2009. Disponível em: <http://www.unasurcds.org/images/stories/ publicaciones/articulo_viceministra_ecu.pdf $>$. Acesso em 23 fev. 2012.

RAMÍREZ, Socorro. El conflicto colombianoj un asunto regional? In: VII CURSO PARA DIPLOMATAS SULAMERICANOS. Rio de Janeiro, 19 de outubro a 12 de novembro de 2009. Palácio Itamaraty. Brasília: FUNAG, 2010. p. 181-202.

SAINT-PIERRE, Héctor. Itamaraty evitou o pior na crise entre Colômbia e Equador. UNESP. Disponível em: <http://www.unesp.br/aci/jornal/235/suplea.php. 2008>. Acesso em: 15 fev. 2012. 
SAINT-PIERRE, Héctor; CASTRO, Gustavo Fabián. "El Consejo Sudamericano de defensa." Boletín RESDAL. v.11, n. 29, Junho 2008. Disponível em: <http://www.resdal.org/ csd/articulo-gustavo-hector.pdf>. Acesso em: 18 fev. 2012.

TEIXEIRA JR. A. W. M. O Conselho de Defesa SulAmericano da Unasul: criação institucional e cultura estratégica. In: OLIVEIRA, Marcos Aurélio Guedes de. (Org.). Comparando a Defesa Sul-Americana. Recife: Editora Universitária UFPE, 2011.p. 127 -147. 